\title{
Life Cycle Assessment (LCA) in building materials industry
}

\author{
Alina Vigovskaya ${ }^{*}$, Olga Aleksandrova ${ }^{1}$, and Boris Bulgakov ${ }^{1}$ \\ ${ }^{1}$ Moscow State University of Civil Engineering, Yaroslavskoe shosse, 26, Moscow, 129337, Russia
}

\begin{abstract}
Environmental issues are becoming more relevant nowadays. The industry is developing and this leads to intensive consumption of natural resources. This fact should make manufacturers think about optimization of the production. The knowledge of life cycle of products to be produced may help to optimize different stages of production. The life cycle assessment (LCA) is a useful tool to reveal information about products in many fields of human activity, and, specifically, in building materials industry. When life-cycle data is available, there appears an opportunity to make relevant changes in the way of extraction, manufacturing, installation and maintenance of products, and, in the end, disposal, recycling or reuse. The paper is concerned with the theoretical aspects of life cycle assessment application in industry of building materials and provides general information on what the LCA is, its origin and development, and possibilities for application.
\end{abstract}

\section{Introduction}

In recent years, sustainable development has become an important issue in our society. Today people use the equivalent of 1.6 Earths to meet the resource needs of daily life and absorb the resulting wastes. This measure means that it now takes the Earth one year and six months to regenerate what we use in a year. If current trends continue, estimates suggest, by the year 2030 we will need the equivalent of two planets [1]

Turning resources into waste faster than they can be regenerated puts the planet into ecological overshoot, a clearly unsustainable condition that we all must address. The linear use of natural resources, treating outputs as waste, is responsible for the toxins that are accumulating in the atmosphere, in water, and on the ground. The pattern of extraction, use, and disposal has hastened depletion of finite supplies of nonrenewable energy, water, and materials and is accelerating the pace of the great problem - climate change [2].

Buildings are responsible for more than 40 percent of global energy use and one third of global greenhouse gas emissions, both in developed and developing countries. The full extent of the lifetime emissions of a building can be best understood by using the life-cycle approach. The life-cycle approach reveals that over 80 percent of greenhouse gas emissions take place during the operational phase of buildings, when energy is used for heating, ventilation, cooling, lighting, appliances, and other applications. A smaller percentage,

\footnotetext{
${ }^{*}$ Corresponding author: alina.vigovskaya@gmail.com
} 
from 10 to 20 percent, of the energy consumed is for materials manufacturing and transportation, construction, maintenance, renovation and demolition [3] (Fig. 1)

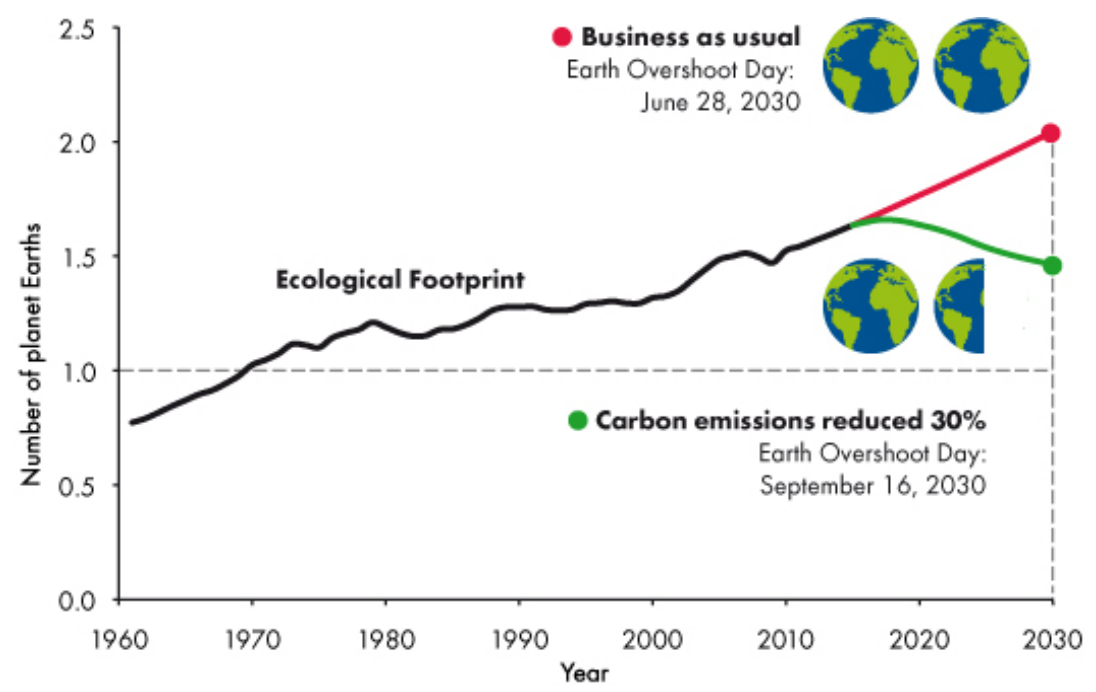

Fig. 1. How many Earth does it take to support humanity?

On the basis of the above information, we can resume, that construction industry, and, specifically, building materials industry, have a significant impact on the environment. For this reason, the unchanged trend of the last decades is tightening environmental requirements for the manufacturing and final products. Road maps for sustainable development of the industry until 2050 aim substantial reduction in emissions to the environment, reduction in use of natural materials and non-renewable energy sources, reduction of waste volume, and increased share of biodegradable materials in the waste composition. Accordingly, the current level of the industry development expects the building materials industry to play the key role in solving relevant environmental problems [4]. Therefore, the design of building products must consider these challenges when creating eco-friendly and socially acceptable solutions, seeing sustainability as a matter of optimization in the use of available resources along the entire product lifecycle.

\section{General information about LCA}

\subsection{A brief history of LCA}

The LCA methodology dates back to 1960s and early 1970s, and focused on issues such as energy efficiency, the consumption of raw materials and, to some extent, waste disposal. In 1969, for example, the Coca Cola Company funded a study to compare resource consumption and environmental releases associated with beverage containers. Meanwhile, in Europe, a similar inventory approach was being developed, later known as the "Ecobalance". In 1972, in the UK, Ian Boustead calculated the total energy used in the production of various types of beverage containers, including glass, plastic, steel, and aluminium. In 1979 Boustead published the Handbook of Industrial Energy Analysis.

While interest in LCA continued, thinking progressed a bit more slowly. It was not until the mid-eighties and early nineties that a real wave of interest in LCA swept over a much broader range of industries, design establishments and retailers. In the early nineties, LCA was used for external purposes, such as marketing [5]. At this time, Society of 
Environmental Toxicology and Chemistry (SETAC) started to be a part of the cause of bringing the LCA specialists together and harmonizing the general structure, methodology and terminology of LCA, which resulted in the SETAC Code of "Practice". From 1994 the International Organization for Standardization (ISO) was involved by taking over what SETAC had initially developed resulting in the ISO 14040 standard series, first published in 1997. This standardization, therefore, created a general methodological framework, which made it easier to compare different LCAs. Since 1990 the building sector has been using LCA and the interest in LCA has been growing fast from the beginning of the $21 \mathrm{st}$ century. Thus, it is an important tool for evaluating buildings. Furthermore, LCA has become a widely used methodology due to its qualitative way to integrate important topics, such as framework, impact assessment and data quality [6, 7].

\subsection{Definition of LCA}

According to ISO 14040 LCA is a "compilation and evaluation of the inputs, outputs and the potential environmental impacts of a product system throughout its life cycle". LCA examines the entire life cycle of a product, from extraction and acquisition of raw material, through energy and material production and manufacturing, to use and end of life treatment and final disposal. ISO 14040 describes four phases: 1) the goal and scope definition: the goal includes the intended application, the reasons for the study, the audience, and whether the results are disclosed to the public, and the scope defines the product to be studied, the functional unit, system boundaries, impact categories, and treatment of uncertainty; 2) life cycle inventory analysis phase (LCI): involves compiling and quantifying inputs and outputs for a product through its life cycle, and collection of the data necessary to meet the goals of the defined study; 3) life cycle impact assessment phase (LCIA): evaluate the significance of the potential environmental impacts for a product system throughout the life cycle of the product.; 4) interpretation: the phase in which the findings of either the inventory analysis or the impact assessment, or both, are evaluated in relation to the defined goal and scope in order to reach conclusions and recommendations. The relationship between these four phases is shown in Figure 2.

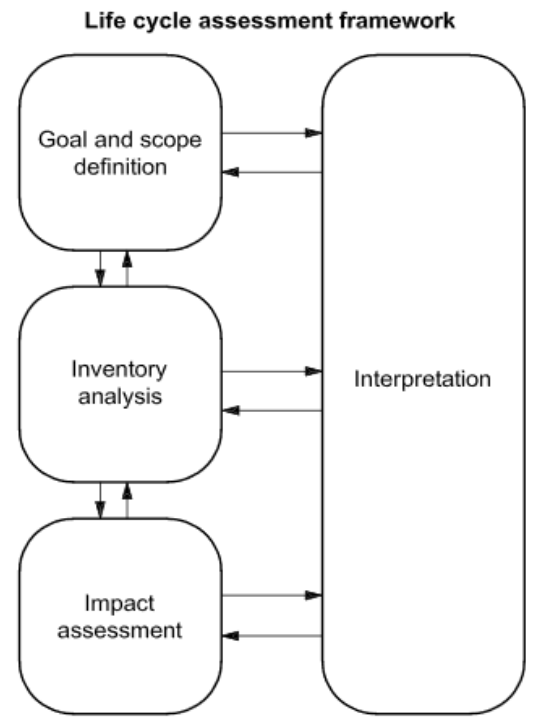

Fig. 2. Relationship of LCA stages according to ISO 14040. 
The scope of an LCA depends on the subject and the intended use of the study. The depth and the breadth of LCA can differ essentially depending on purposes of a particular LCA [8].

\section{Application of LCA}

\subsection{LCA in ecolabelling}

There are 3 types of environmental product labels: category labels - Type I, ISO 14024 [9]; self-declared environmental claims - Type II, ISO 14021 [10], and EPDs, ISO 14025.

The EPD, an internationally standardized document providing quantified environmental impacts over the life cycle of a product, refers to the type III environmental declarations, that, as defined in ISO 14025, are primarily intended for use in business-to-business communication, but their use in business-to-consumer communication under certain conditions is also possible [11]. The purpose of the EPD is to provide quantified environmental information about the life cycle of a product in order to facilitate environmental comparison between products that perform the same function. There are many EPD programmes around the world, and all of them are operated by product category rules (PCR), which set out the specific guidelines and requirements for the development of the LCA study [12]. Nevertheless, PCRs may be developed by anyone who calls themthelves a programm opeartor, causing substantial variation between these rules. Ideally, EPDs enable fair comparison between similar products adhering to comparable PCRs and summarize third-party verified LCA results [13].

\subsection{Green building assessement and certification programs, and the role of EPDs}

There are many programs in the world, that have been developed to assess environmental and energy impacts of buildings. The first environmental certification system was created in 1990 in the UK, The Building Research Environmental Assessment Method (BREEAM).

In 1998 the Leadership in Energy and Environmental Design (LEED ${ }^{\circledR}$ ) Green Building Rating System was introduced based quite substantially on the BREEAM system. LEED is a framework, developed by the U.S. Green Building Council, for identifying, implementing, and measuring green building and neighborhood design, construction, operations, and maintenance.

LEED is a voluntary, market driven, consensus-based tool that serves as a guideline and assessment mechanism, seeks solutions to optimize the use of natural resources, promote regenerative and restorative strategies, maximize the positive and minimize the negative environmental and human health consequences of the construction industry, and provide high-quality indoor environments for building occupants [14].

"Materials and Resources" is one of the LEED credit categories, that project team must work at to obtain the LEED certificate. The credit "Building Product Disclosure and Optimization - Environmental Product Declarations" is one of the credits of this category, that contains requirements to provide EPDs for defined quantity of materials. This credit is aimed at purchasing the products and materials, which life-cycle information is available and that have environmentally, economically, and socially preferable life-cycle impacts [15].

A couple of other programs that use LCA tool to analyze the sustainable approach during design, construction, operation and maintenance of buildings are GBI (Green Building Initiative; the U.S.), DGNB (Deutsche Gesellschaft für nachhaltiges Bauen e.V. German Sustainable Building Council; Germany), and others. 


\section{Conclusions}

The following conclusions were drawn from this study:

1. Today the humanity faces a lot of problems, regarding to the environment. Construction industry, and, specifically, building materials industry, have a great impact on this issue, and one of the greatest problems these industries cause - is climate change.

2. LCA is a "compilation and evaluation of the inputs, outputs and the potential environmental impacts of a product system throughout its life cycle". The LCA methodology dates back to 1960 s, and focused on issues such as energy efficiency, the consumption of raw materials, and now is widespread in many fields of human activity.

3. LCA has four phases: 1) the goal and scope definition; 2) life cycle inventory analysis; 3) life cycle impact assessment; and 4) interpretation.

4. There are three types of ecolabelling of materials, the most detailed one is type III EPD, a set of quantified environmental data consisting of pre-set categories of parameters based on LCA. EPDs are usefull for business-to-business communications, and are documents, that will be usefull while obtaining a certification of any existing green building assessment programs, such as BREEAM, LEED, DGNB and others.

In addition, it is important to note, that the LCA tools are not widely used in Russia, but they could solve relevant problems in building materials industry, like: responsible extraction of raw materials, transportation, implementation of new effective technologies in manufacturing, that will reduce resources consumption, reduce emissions of harmful substances, waste generation, and etc. For this reason, the problem of use of LCA tool in Russia is relevant and required further research for different types of building materials.

\section{References}

1. W.E. Rees, Ref. Mod. in Life Sc. 24 (2017)

2. G. Bridge, Int. Enc. of Hum. Geo., 261 (2009)

3. M. A. Khana, M. Z. Khanb, K. Zamanc et.al. Ren. and Sust. En. Rev., 29, 336 (2014)

4. The order of the Government of the Russian Federation, No 868-p, May 10, 2016

5. D. Elcock, Life-Cycle Thinking for the Oil \& Gas Exploration \& Production Industry, Arg. Nat. Lab., 160 (2007)

6. B. Soust-Verdaguer, C. Llatas, A. García-Martínez, En. and Build., 136, 110 (2017)

7. A. Pöyry, Master's Thesis Department of Real Estate, Planning and Geoinformatics, School of Engineering, Aalto University, 6 (2014)

8. ISO 14040, (2006)

9. ISO 14024, (2002)

10. ISO 14021, (2016)

11. ISO 14025, (2006)

12. M.D. Bovea, V. Ibáñez-Forés, I. Agustí-Juan, Eco-eff. Constr. and Build. Mat., 125 (2014)

13. M. D. C. Gelowitz, J.J. McArthur, Proced. Eng., 145, 59 (2016)

14. W. L. Lee, J. Burnett, Build. and Environ., 43, 1882 (2008)

15. G.E. Marjaba, S.E. Chidiac, Build. and Environ., 101, 116 (2016) 